\title{
Workplace pro-environmental behaviors in small and medium-sized enterprises: an employee level analysis
}

Adeleke Oladapo Banwo* (i) and Jianguo Du

\author{
* Correspondence: \\ lekebanwo@outlook.com \\ School of Management, Jiangsu \\ University, 301, Xuefu Road, \\ Zhenjiang, Jiangsu Province, China
}

\begin{abstract}
Employees spend much time in the workplace; however, most research have not examined employee's workplace pro-environmental behavior in small and mediumsized enterprises in developing countries. This paper examines the direct and indirect effect of predictor variables on employee's workplace pro-environmental behavior using the comprehensive action determination model. Employees working in small and medium-sized enterprises $(n=296)$ in three cities in Jiangsu Province, China, were chosen through snowball, convenience sampling, and survey data were obtained via the administration of self-report questionnaires. Principal component analysis with orthogonal rotation (varimax) was used to subject all measures to uni-dimensionality test using an eigenvalue $>1$ criterion. Regression analysis, exploratory factor analysis, and structural equation model were used for data reduction and analysis using SPSS version 22. The findings indicate that perceived behavior control, intention to act, sustainable actions, environmental attitude, and social norms had a direct effect while information need, habit strength, and situational conditions had an indirect effect on workplace pro-environmental behavior.

Keywords: China, Comprehensive action determination model, Context, Employees, Jiangsu Province, Small and medium-sized enterprises, Workplace pro-environmental behavior
\end{abstract}

\section{Introduction}

Small and medium-sized enterprises (SMEs) are recognized as the most important business segment in developing countries, mainly due to their numbers, collective size, and roles in sustaining economic stability by providing means of livelihood for their citizens (Ayyagari, Demirguc-Kunt, \& Maksimovic, 2014). They account for more than $90 \%$ of businesses globally; in the UK, the USA, Europe, the Organization For Economic Cooperation and Development (OECD), and 99\% of private sector business (Ayyagari, Beck, \& Demirguc-Kunt, 2007; Jamali, Lund-Thomsen, \& Jeppesen, 2015). In most economies, SMEs contribute to economic growth, development, job creation, employment, poverty reduction, and reviving their economies in times of depression and recession (Ayyagari, Demirgüç-Kunt, \& Maksimovic, 2011; Bauchet \& Morduch, 2013; Fakieh, Blount, \& Busch, 2016).

(C) The Author(s). 2019 Open Access This article is distributed under the terms of the Creative Commons Attribution 4.0 International License (http://creativecommons.org/licenses/by/4.0/), which permits unrestricted use, distribution, and reproduction in any medium, provided you give appropriate credit to the original author(s) and the source, provide a link to the Creative Commons license, and indicate if changes were made. 
However, the activities of SMEs are a major cause of environmental problems (Parker, Redmond, \& Simpson, 2009). Employees are the principal actors in SMEs, and contextual predictors of their environmental behaviors have been a neglected area of research. Previous findings suggest that human behaviors are the major underlying cause of climate change and environmental issues (Steg \& Vlek, 2009). Similarly, few researchers have addressed the issue of SMEs workplace pro-environmental behavior (Boiral, Paillé, \& Raineri, 2015; Ones \& Dilchert, 2013).

In addition, previous works failed to address the dynamics of SME employee's workplace pro-environmental behavior (WPEB) in China (Parker et al., 2009). SME WPEB are still poorly understood, though they constitute the most common enterprises in China and other developing countries. Most studies tend to focus on pro-environmental behavior at the organizational level (Cantor, Morrow, \& Montabon, 2012; Klöckner, 2013; McDonald, 2014).

This study aims to broaden current knowledge on contextual predictors of SMEs employee's WPEB in Jiangsu Province, China. This paper is divided into three sections. The first section gives a brief overview of the literature review and theoretical framework. The second section examines SME environmental law nexus. The third section focuses on hypothesis testing, data analysis, and results. The conclusions and recommendations are outlined in the final sections.

\section{Literature review}

A recent review of the SMEs literature in the last decade confirms an increasing number of studies focused on sustainability, environmental behavior, and green initiatives.

Hines, Hungerford, and Tomera (1987) were among the first researchers to conduct a meta-analysis of responsible environmental behavior. Twenty years after, Bamberg and Möser's (2007) meta-analysis confirmed mean correlations between psycho-social variables and pro-environmental behavior (PEB) and found that attitude, behavioral control, and personal moral norm are direct predictors of PEB intention, while problem awareness is an indirect predictor.

PEB are multidimensional, multidisciplinary, and a complex construct that involves different elements (Gifford \& Nilsson, 2014; Larson, Stedman, Cooper, \& Decker, 2015). Defining this construct has remained complex due to perspectives adopted by scholars (Jensen, 2002; Robertson \& Barling, 2013; Turaga, Howarth, \& Borsuk, 2010).

PEB is made up of a combination of pro-social variables, self-interest, and concern for the environment (Eisenberg, Lennon, \& Roth, 1983; Steg \& Vlek, 2009). Similarly, the approaches and perspectives used by researchers in investigating PEB show divergent approaches by two schools of thought; the pro-socially motivated approach uses the norm activation model as its theoretical basis while the self-interest school of thought relies on Ajzen (1991) theory of planned behavior. When grouped together, the norm activation model, value-belief-norm theory, and identity theory all have a normative premise as their basis.

Steg and Vlek (2009) defined PEB as "behaviors that harm the environment as little as possible or even benefits the environment". Employees are the central drivers and important in ensuring the successful adoption of environmental initiatives. 
Steg, Bolderdijk, Keizer, and Perlaviciute's (2014) change and quality perspective posits environmental behavior as all types of behavior that change the availability of materials or energy from the environment. This quality perspective connotes environmental behavior "as any action that affects the quality of the environment in either a positive or negative way either resulting from or not resulting from environmental intentions." PEB differ and often the resultant focal behaviors are an effect of an interplay of multi-variables (Paillé \& Mejía-Morelos, 2014).

Boiral et al. (2015) offer a rather robust definition of PEB as comprising "all types of voluntary or prescribed activity undertaken by individuals that aim to protect the natural environment or improve organizational practices in these areas." Therefore, the premise for PEB revolves around voluntary behaviors, initiatives, and stakeholders at microlevel, macrolevel, and beyond the workplace (Lülfs \& Hahn, 2014).

In recent nomenclatures, environment behavior and PEB refer to diverse sets of behavioral actions focused on the environment (Cantor et al., 2012). Several perspectives have also been advocated and investigated by researchers: green behaviors (Ones \& Dilchert, 2013), environmentally responsible and sustainable behaviors (De Young, 2000), eco-friendly behaviors and initiatives (Dahm, Samonte, \& Shows, 2009), and pro-environmental behaviors and behavioral intentions (Kollmuss \& Agyeman, 2002).

Steg et al. (2014) integrated framework for environmental behavior (IFEB) investigated the variables and processes in PEB through the lens of contextual factors, goals, and values. For example, the decision to take a public bus daily to the office may be the resultant effect of some underlying factors such as a reduction in bus fares, provision of free buses, or a choice to reduce gas emission. The decision and motives underlying any behavior are influenced by hedonic, normative and gain goals within the individual (Lindenberg \& Steg, 2007).

Normative goals make people determine the impact of their actions on the environment, increasing sensitivity consciousness of actions and effects. Gain goals relate to affect elements such as personal status, position, income, and what positive or negative change this will have on the individual's behavior. Hedonic goals focus on individual feelings in contextual situations. The interplay of these goals does not follow any hierarchical pattern but dependent on four dimensions, information, knowledge, alternatives, actions, and context. The dominance of any goal in the decision-making reflects the nature of coherence or disparity among the subset goals that may enhance or diminish the focal goals (Lindenberg \& Steg, 2007).

Environmental behavior is impacted by subtle cues in the environment (Osbaldiston \& Schott, 2011) and motivations arise for several reasons and not necessarily an intent to protect the environment. Individuals are daily confronted with making choices, which are complex and caught in determining what is construed as the most appropriate behavior vis a vis what is most convenient. Other studies examined SMEs ability to engage in sustainable environmental practices and found that size and other key factors influence SMEs employee attitude towards the environment (Etzion, 2007).

Every enterprise belongs to an industry, and the majority of SMEs in less-developed countries engage in retail trade and services with a wide range of stakeholders at different levels, such as government, community, non-governmental organization, environmental activists, consumers, the public, and investors. 


\section{Theoretical framework}

Attempts at investigating and understanding environmental behavior in different contexts have resulted in diverse theories. Each theory's shortcoming is due to the narrow focus on some elements as key predictors of behavior, failing to present a multidimensional and robust measurement of environmental behavior. Unitary predictor like intention is the premise of Azjen theory of planned behavior (Ajzen, 1991), Fishbein theory of reasoned action (Fishbein, 1979), personal norms in Schwartz norm-activation theory (Schwartz \& Howard, 1981), and habit in Triandis theory (Triandis, 1979).

This led to Klöckner and Blöbaum (2010) comprehensive action determination model (CADM) which suggests that intention, context, and habits are key determinants of behavior. Empirical studies reaffirm the importance of intention as a key mediator of direct predictors (Bamberg \& Möser, 2007). However, depending on the context, the interplay of attitude, perceived behavioral control and norms exert influences on intention in the decision-making process. They also reiterate the urgency and the need to integrate the models to mitigate their individual limitations through the adoption of a unified and robust model.

The CADM argues that both intention and perceived behavioral control do not suffice to predict behavior always and introduces habit strength as a third predictor of behavior (Klöckner, 2013). Habit strength is a major moderator between the individual's intention and actual behavior. Where the habit is strong, influences of attitudes, norms, and perceived behavioral control may not necessarily lead to the desired PEB unless interventions are used to influence and weaken the habit systematically.

Habits depict repeat action pathways, which have become relatively stable and impulsively accepted, and manifest as the choice pattern of behavior (Klöckner \& Matthies, 2012). It also includes cognitive structures that automatically determine future behaviors by linking specific situational cues to behavioral patterns (Robertson \& Barling, 2015). Likewise, the situational cue an individual is exposed to influences the relative intensity of his habit and reduces it where such cues are non-existent. When an individual repeats a particular behavior such as throwing trash in the drainage in his environment, it becomes his first line of spontaneous behavior if given some opportunity in a different context. Every employee has a tendency to exhibit innate habit, which may be in consonance or dissonance with sustainability goals of the enterprise and constitute a strong influence and predictor of behavior. Habit strength can pose severe risks which could be easily manipulated in different contexts. Strong habits can exert a negative correlation between norms, intention, and actual behavior, and when inferences are drawn from contextual cues, it becomes easy to determine the frequency of the habit and potential ability to impact on behaviors. Scholars have investigated the relationship between intention, personal norms, and habits to determine the effect of the dimensions of habit on behavior (Ouellette \& Wood, 1998).

Verplanken and Aarts (1999) stated that primary habits connote the totality of a spontaneous and mindless reaction to specific actions in stable contexts and the weakness or strength of the habit is fundamental in achieving desired and chosen paths of actions and goals. In most contexts, the behavioral performance is impulsive and may not take a rational approach and performance (Ruepert et al., 2016). Since habits are spontaneous, rational decision-making is reduced and such behaviors rarely take cognizance of the implications on environmental behaviors. The CADM in Fig. 1 


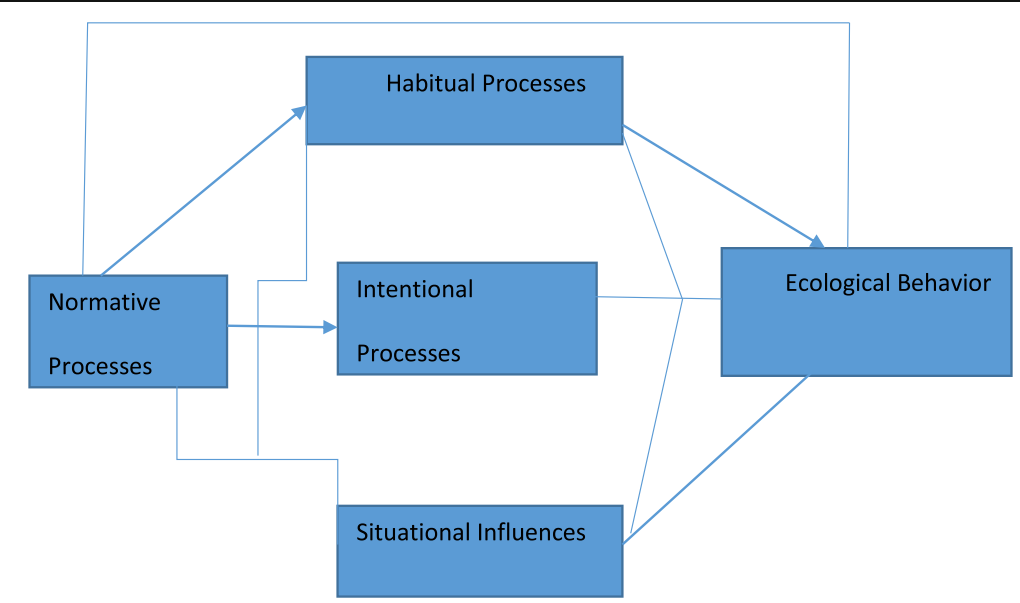

Fig. 1 Comprehensive action determination model. Adapted from Klöckner and Blöbaum (2010)

stresses the importance of understanding behavioral change interventions that may be suitable to modify and alter habits in conformity with WPEB. Where the habit strength is negative, then interventions alone do not suffice without a critical modification of situational factors such as availability of waste bins, public bicycles, and transport that can easily facilitate the gradual change in behavior pattern. The overriding role of context in workplace settings could serve to either inhibit or enhance WPEB, and the existence and absence of requisite facilities and intervention tools have an impact on employee WPEB (Unsworth, Dmitrieva, \& Adriasola, 2013).

CADM model equation

where

$$
\begin{aligned}
& \mathrm{Np}=(\mathrm{Sn}+\mathrm{Pn}+A(N+C) \\
& \mathrm{Ip}=(I+A) \\
& \mathrm{Sp}=C(O+S)
\end{aligned}
$$

where

1. Normative process comprises of social norms $(\mathrm{Sn})$, personal norms $(\mathrm{Pn})$, awareness of need (An) and awareness of consequences.

2. Internal process (Ip) comprises of intentions (I) and attitude (A).

3. Situational process $(\mathrm{Sp})$ comprises of constraints $(C)$, objective $(O)$, and subjective $(S)$.

Each individual has a set of personal norms, which are dependent on the environmental subset, which he belongs. Personal norms interact with business and social norms, and often a convergence of these norms exist in a state of inertia and result in the exhibition of stable preferences over a long period. In essence, contextual cues affect norms and intentions (Ajzen, 1991) and in the medium to long term it activates and deactivate certain aspects of an individual personal norm. Conversely, habits are peculiar behavioral pattern arising from a build-up of a series of past behavior patterns (Ajzen \& Madden, 1986). We assert that these variables and predictors are complex 
and interwoven and thus time, personality profiles, and contexts determine their nature of interaction and outcome as positive or negative environmental behavior.

Personal norm in the CADM is depicted by

$$
\mathrm{Pn}=\mathrm{Na}+\mathrm{Ca}+\mathrm{Pbc}
$$

where $\mathrm{Na}=$ need awareness, $\mathrm{Ca}=$ consequence awareness, and $\mathrm{Pbc}=$ perceived behavioral control.

Furthermore, personal norms cannot exist in isolation and the existence of exogenous influences enshrined in social and business norms vary from one business location and industry to another. Using a system perspective, personal norms could be subsumed by social and business norms, if the individual expects to remain within such settings.

The empirical validity of the CADM model rests in its ability to explain variations higher when compared with other PEB theories (Klöckner \& Blöbaum, 2010). Still, an individual can be influenced by the normative process (subjective norms, personal norms, and values). This does not always result in the desired PEB but is mediated by subsets of habitual, intentional processes, and situational influences.

Furthermore, McLeod (2009) stated that "A schema can be defined as a set of linked mental representations of the world, which we use to understand and respond to situations." These mental processes depict organized knowledge acquired over a span of time commonly used by social psychologist to connote how individuals use their learning curves and exposure in real-life problem-solving situations.

\section{SME-environmental Laws Nexus}

The 1972 Stockholm Conference on Human Environment served as a pioneer motivation for the series of environmental management laws and stratified governance mechanism (Dixon, Scura, Carpenter, \& Sherman, 2013; He, Lu, Mol, \& Beckers, 2012). Moreover, the enactment of environmental laws and policies in China since the 1980s focused on improving environmental practices, reducing rising health problems, environmental deterioration, and degradation (He, Zhang, Mol, Wang, \& Lu, 2014; Zhang et al., 2008). It is apparent that implementation and practicability remains a major problem for the Chinese government (Economy, 2011; Wang, 2013). China has more than 50 environmental laws and a signatory to over 46 international environmental convention accords, yet poor environmental behavior and management is common in different provinces (Alam, 2013). The central government provides leadership and formulates the environmental laws for implementation by the leadership of provinces and autonomous regions. Zhang et al. (2008) found that there are over 3854 supervisory and enforcement offices with over 50,000 workforces. The vagueness, contradictory nature, and low level of environmental consciousness of local residents are some of the implicit factors that have hindered the full-scale success of China's multilevel environmental laws (Canfa, 2006; Kostka, 2014; Xi et al., 2015). Also, gaps in enactment and implementation of environmental laws in China have continued to increase due to the economy's fragmented model, lax enforcement, lack of incentives, and regional autonomy of provinces (Eaton \& Kostka, 2014).

It is evident that relying solely on government regulations has yielded a minimal result and this reinforces the current change in approach to embrace multilevel stakeholders and pressure groups such as households, neighbors, community, and non-governmental organizations (Hannigan, 2014). 
The research on pro-environmental discourse in China is supported by the ineffectiveness of the command and control approach which in practical terms are plagued by weak institutional frameworks (Liu et al., 2010; Zhang \& Wen, 2008). Recent enactments such as cleaner production, environmental behavior practices, and initiatives targeted at SMEs are hindered by a dearth of appropriate economic and social incentives. There are variances in levels of enforcement and environmental awareness in various provinces, given the resource disadvantage of SMEs (Su, Heshmati, Geng, \& Yu, 2013).

Contextual elements and social and environmental awareness can have a positive impact on SMEs and increase their current level of awareness (Kollmuss \& Agyeman, 2002; Liu \& Bai, 2014). SMEs in China are exposed to multi-layered environmental watchdogs in their environment aside from the government. These sources of pressures are becoming increasingly complex as they all try to monitor and advocate for proper environmental management system and behaviors. Common sources of pressures include local residents, trade associations and groups, shareholders, consumers, employees, and non-governmental organizations (NGO) (Li, Liu, \& Li, 2012; Sudbury Riley, Kohlbacher, \& Hofmeister, 2012).

It is widely acknowledged that local communities provide information to government and local authorities of activities that are inimical to their local environment (Xu et al., 2013; Zhang et al., 2008). They are motivated by the need to protect their source of livelihood, reduce health hazards arising from pollution, and make firms more environmentally responsible and conscious of their actions (Chen et al., 2013). Research affirms that firms are more environmentally conscious in urban provinces and often lax in rural areas where weak institutional frameworks exist (Harris, 2006; $\mathrm{Yu}, 2014$ ). For example, competition is high among the pickers of different recycling products which are sold for some token consideration (Troschinetz \& Mihelcic, 2009; Xiao \& Hong, 2010). In addition, while the pickers solve some environmental problems, on the one hand, the companies that use these raw materials often do not discharge their effluents in an environmentally friendly manner, thereby causing a higher concentrated level of pollution and exposing local residents to water-related pollution.

Current literature on workplace pro-environmental behavior adopts a novel categorization of four fundamental influences of behavior as follows:

Motivational, interpersonal, intrapersonal, and external factors depicted as

$$
\text { WPEB }\left(E M I_{\mathrm{ab}} P\right)
$$

where WPEB represents workplace pro-environmental behavior

$E=$ external factors, $\mathrm{M}=$ motivational factors, $\mathrm{Ia}=$ interpersonal factors, $\mathrm{I}_{\mathrm{b}}=$ intrapersonal factors.

This is further denoted by the following:

$$
\left.E=O\left(C^{2} S P\right)+\mathrm{ES}_{\mathrm{i}} S C\right)
$$

External Factors $(E)$ are denoted by organizational context $(\mathrm{O})$, climate $\left(\mathrm{C}^{2}\right)$, structure $(\mathrm{S})$, policies $(\mathrm{P})$ and environment management systems (ES), size (S), situational constraints $(C)$. 


$$
M=I(\mathrm{Pbc}, \mathrm{Im})+E(\mathrm{Ws}, \mathrm{Em})
$$

Motivational Factors $(M)$ are denoted by internal drivers $(I)$ such as perceived behavioral control $(\mathrm{Pbc})$, intrinsic motivation $(\mathrm{Im})$ and external drivers $(E)$ such as external motivation (Em), work satisfaction (Ws).

$$
\mathrm{Ia}=(S, I, \mathrm{Dn})+(M, \mathrm{Gd}, \mathrm{Sc})
$$

Interpersonal Factors (Ia) are denoted by social (S), injunctive (I), and descriptive norms $(D)$ and management support $(M)$, group dynamics $(\mathrm{Gd})$, and social class $(\mathrm{Sc})$.

$$
\mathrm{I}_{\mathrm{b}}=D(H, A, R, M, S+I, E)+A\left(A_{2} I\right)+V(P, E, A)
$$

Intrapersonal Factors $\left(I_{b}\right)$ are denoted by personal demographic elements like household size $(H)$, age $(A)$, residence/location $(R)$, marital status $(M)$, gender/sex $(S)$, income $(I)$, education $(E)$, attitude $(A)$, awareness $\left(A_{2}\right)$, intention $(I)$, and values $(V)$ embodied by personal norms $(P)$, environmental concern $(E)$, and ascription of responsibilities (A). Adapted from (McDonald, 2014).

\section{Study location}

Small and medium-sized employees in China were the target population in this study. China is Asia's largest country and also the most populous nation in the world. According to China's ministry of commerce, SMEs in China exceed four million and contributes more than 58\% of GDP and taxes; they spearhead exports and job creation yearly, accounting for about $68 \%$ and $75 \%$, respectively. The study location was Jiangsu Province in Eastern China, a major economic hub along the Yangtze River delta. With an average population of 79 million, its strategic location shares boundaries with Shandong Province (North), Shanghai and Zhejiang Province (South), and Anhui Province (West) (Huang et al., 2015).

\section{Analysis and results}

The aim of the study was to investigate contextual predictors of SMEs WPEB. Consequently, convenience and snowball sampling method were chosen because it is the most practical method for the hard to reach sample respondents. We chose both methods based on recommendations of (Atkinson \& Flint, 2001). The sample composed of employees working in SMEs in cities in Jiangsu Province (Zhenjiang, Yangzhou, and Danyang). The sample size/response rate $(N=296,88 \%)$ comprised of self-report questionnaires completed by SME employees while 40 (12\%) uncompleted questionnaires were rejected. The survey was administered with the assistance of Chinese friends working in SMEs and cluster locations using online survey links.

Blok, Wesselink, Studynka, and Kemp (2015) questionnaire and self-report habit index were adapted for the measure items and translated to the Chinese language (Verplanken \& Orbell, 2003). Self-reporting questionnaires are commonly used in environmental psychology studies (Beaton, Bombardier, Guillemin, \& Ferraz, 2000). We adapted the questionnaires to fit the semantics, context, and contents of the target language and meet the content validity criteria (Wagner et al., 1998). The translation process included, back translation, expert committee review, and pretesting based on the recommendations of 
Beaton et al. (2000); Brislin (1970). The measure items are environmental behavior, attitude, information need, intention to act, environmental awareness, perceived behavioral control, situational factors, social norms, and habit strength are described below:

1. Pro-environment behavior (PEB): To measure PEB employees were asked to indicate the extent to which they engaged in the following environmental behaviors relating to energy use, printing, sustainable consumption, shopping, computer use, light use and recycling using a 5-point Likert type scale from 1 (never) to 5 (always).

2. Attitude to PEB measured employees' attitude in the workplace, with items such as "I am in favour of behaving pro-environmentally in the workplace," "I think the PEB in the workplace is good," "I was briefed of PEB in my workplace," and "I think too much attention is given to $\mathrm{PEB}$," on a 5-point Likert scale ranging from 1 (strongly disagree) to 5 (strongly agree), high score indicated positive PEB attitude and vice-versa.

3. Information need: Information need was obtained by asking respondents, whether they want to be informed about environmental impacts of their behavior, environmental initiatives, learning opportunities for environmental friendly behaviors and cost of energy, water, and paper used in their department and groups. All the items were scaled from 1 (never) to 5 (always).

4. Environmental awareness: was modified and measured by using 8 scales out of the 12-item scale to assess the employees level of environmental awareness (Gatersleben, Steg, \& Vlek, 2002). Items included "Environmental pollution affects my health," "I walk often within the workplace rather than taking a car/cab/bike," "I commute daily to work by driving," "I use public transport like buses and cabs," "Environmental problems have consequences for my life," "I am unaware of the effect of my behavior on the environment," "Environmental problems are a risk for the future of my children," and "I use my phone daily and switch off my phones when I want to sleep" on scales ranging from 1 (never) to 5 (always).

5. Perceived behavior control: ability to engage in PEB within the workplace had four measure items, and a low score implies low perceived behavior control. An inability to practice environmental behaviors and a high score show high ability of perceived behavior control.

6. Situational factors: measured contextual issues in the workplace that could enhance or inhibit the ability to exhibit positive environmental behaviors. The 3-item questions depicted the ease and difficulty in each situation and responses were measured on a 5-point scale from strongly disagree to strongly agree. The lower the score, the more difficult the possibility to act in an environmentally friendly manner.

7. Self-report habit index: had 12 measure items with a 5-point scale from strongly disagree to strongly agree. A low score confirms low or poor habit strength and a high score suggest high habit strength could take precedence in contexts.

8. Sustainable actions: measured employee sustainable behaviors with 6 measure items and included questions such as "I prefer to buy green products and check if it will harm the environment," "I switch off my computer/notebook when I leave my office for a long time," "I switch on lights when I come to the office/Shop in the morning and leave them on." 
Table 1 Profile of the respondents

\begin{tabular}{|c|c|c|c|}
\hline & & Frequency & China \\
\hline \multirow[t]{3}{*}{ Gondor } & male & 133 & 45 \\
\hline & fomale & 162 & 55 \\
\hline & $\begin{array}{l}\text { Unolassified } \\
\text { Total }\end{array}$ & 296 & 100.0 \\
\hline \multirow[t]{5}{*}{ Ago } & below 21 & 75 & 25 \\
\hline & $21-30$ & 154 & 52 \\
\hline & $31-40$ & 52 & 13 \\
\hline & $41-50$ & 15 & 5 \\
\hline & $\begin{array}{l}51 \text {-Above } \\
\text { Total }\end{array}$ & $290^{\circ}$ & 100.0 \\
\hline \multirow[t]{4}{*}{ EMancitiona' } & Middle School & 7 & 26 \\
\hline & $\begin{array}{l}\text { Figh sonool } \\
\text { graduate }\end{array}$ & 151 & 51 \\
\hline & University & 60 & 22 \\
\hline & Undassified & & 1 \\
\hline \multirow{6}{*}{ Nompioyees } & $\begin{array}{l}\text { Total } \\
\text { 1-g employees }\end{array}$ & 296 & 100.0 \\
\hline & $10-49$ & 90 & 30 \\
\hline & 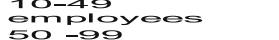 & 84 & 28 \\
\hline & SOMployoos & 39 & 13 \\
\hline & 全mpioyees & 83 & 28 \\
\hline & Total & 296 & 100.0 \\
\hline
\end{tabular}

9. Social norms: employees were asked what in your opinion should your colleagues do in the workplace regarding recycling, printing and copying double-sided, and usage of plastic bottle and paper cups.

Table 1 shows the composition of respondents used in this study. The sex composition includes $55 \%$ female and $45 \%$ Male. The respondent's age were classified in four groups (below 21, 21-30, 31-40, and 41-50) and the survey results show that more than $50 \%$ of the SME employees were aged between 21 years and 30 years $(52 \%)$ and $25 \%$ were aged less than 21 years. Similarly, $51 \%$ of the respondents were senior high school graduates, $26 \%$ Junior high school, and $22 \%$ had university degrees. It is plausible to assume that both junior and senior school graduates possess technical school experience and education. The employee size distribution was fair among enterprises with 1-9 employees (30\%), 10-49 employees (28\%), and above 100 employees (28\%).

The survey questionnaire comprised of multiple Likert scale questions and the internal consistency was checked using Cronbach alphas. Tavakol and Dennick (2011)

Table 2 Reliability test, F-test, KMO, and Bartlett's test

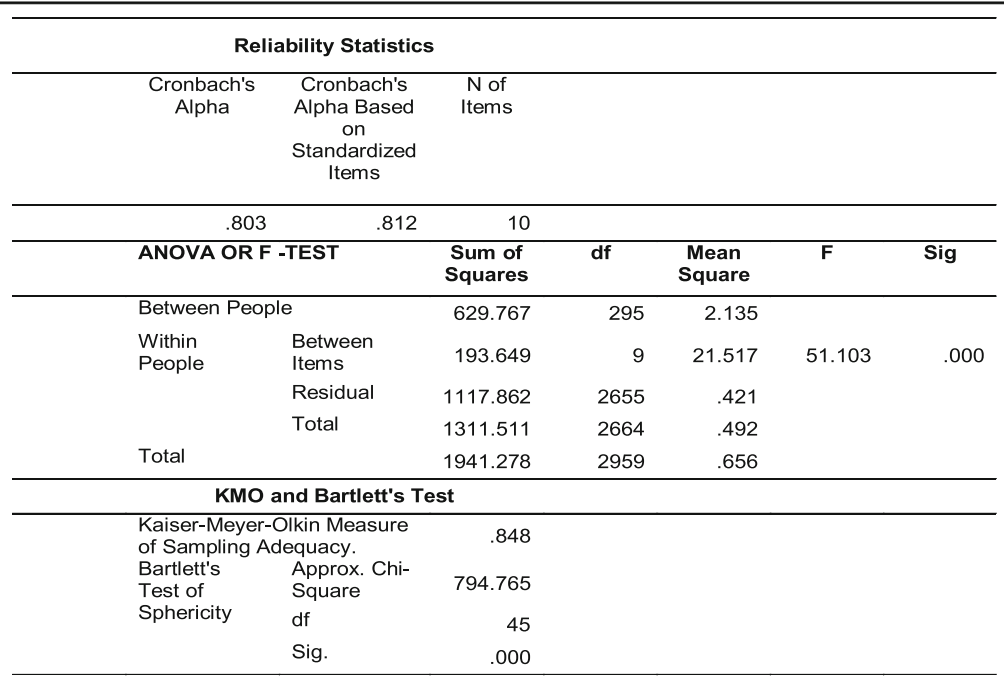


confirm the usage of Cronbach alpha in determining the extent to which all the items in a survey measure the construct. They also stated that it is important to determine the Cronbach alpha coefficient before survey data is used for research to ensure validity. The Nunnally and Bernstein (1994) and Vaske, Beaman, and Sponarski (2016) recommendation on Cronbach alpha was followed and the Cronbach alpha based on standardized items is .812 (see Table 2) which exceeds the threshold of .70, and an indicator of the reliability of measurement scales and items. Second, an analysis of variance (ANOVA) was done and the general rule states, "where $p$ is less than .05 , the result is statistically significant." ANOVA shows the level of difference between two or more means to be significant or not. There was a statistically significant difference between groups as determined by ANOVA $\left(F_{1,9}=51.1, p<.000\right)$ suggesting a good fit for the model. The value for the $F$-statistic is the mean square (regression) divided by the mean square (residual) (See Table 5). Third, the survey data was tested for factor dimensions and sample adequacy using Kaiser-Meyer-Olin measure of sampling adequacy and Bartlett test of Sphericity.

The general criterion is that the sample is adequate if the KMO value is greater than .5 (KMO $\geq .50)$. In Table 2 , KMO of .84 and Bartlett's test with a value of 794.765 , $p<.05$ (p.b.000), both support the factorability of the correlation matrix.

\section{Principal component analysis (total variance explained (eigenvalues)}

A principal component analysis (PCA) with orthogonal rotation (Varimax) was used to subject all measures to uni-dimensionality test using an eigenvalue $>1$ criterion. PCA is a method of data reduction used to explain the variance of the observed variables using composite variable (components). Though other rotation methods also have their relative strength (Osborne \& Costello, 2009), the preference for the varimax rotation method lies in its ability to give an ideal factor pattern and as an iterative method (Hendrickson \& White, 1964). The analysis is forced to select factors with eigenvalues greater than one. This criterion is based on several rules of thumb such as the Guttmann-Kaiser Criteria (Cliff, 1988; Yeomans \& Golder, 1982) and retaining components which account for about $70-80 \%$ of the variance.

\section{Model summary and Durbin-Watson test}

Scholars have argued that having a high $R$ squared can be misleading and thus the size of $R^{2}$ and adjusted $R^{2}$ should be dependent on the objective of the study, subject area, and analysis intended, and thus other tests for multi-collinearity (Durbin-Watson test) was conducted.

Table 3 Regression model summary and Durbin-Watson test

\begin{tabular}{|c|c|c|c|c|c|c|c|c|c|c|}
\hline \multicolumn{11}{|c|}{ Model summary ${ }^{\text {b China(T1) }}$} \\
\hline \multirow[t]{2}{*}{ Model } & \multirow[t]{2}{*}{$R$} & \multirow[t]{2}{*}{$R$ square } & \multirow{2}{*}{$\begin{array}{l}\text { Adjusted } \\
R \text { square }\end{array}$} & \multirow{2}{*}{$\begin{array}{l}\text { Std. error } \\
\text { of the } \\
\text { estimate }\end{array}$} & \multicolumn{5}{|l|}{ Change Statistics } & \multirow{2}{*}{$\begin{array}{l}\text { Durbin- } \\
\text { Watson }\end{array}$} \\
\hline & & & & & $R$ Square change & F change & df1 & $\mathrm{df2}$ & Sig. F change & \\
\hline 1 & $.425^{\mathrm{a}}$ & .181 & .155 & .455 & .181 & 7.009 & 9 & 286 & .000 & 1.804 \\
\hline
\end{tabular}

aPredictors: (Constant), HABTOTAL, ATTTOTAL, SUSTOTAL, INFNTOTAL, SNTOTAL, SITTOTAL, EATOTAL, PBCTOTAL, INTACTTOTAL 
In Table 3, the $R$-value is .425 and indicates that the independent variables explain $43 \%$ of the variability in the dependent variable. $R$-value shows the level of correlation between the observed and predicted values of dependent variable. The coefficient of determination also known as $R$ squared $\left(R^{2}\right)$ value is .181 and indicates that the proportion of variance in the dependent variable (pro-environmental behavior) that is explained by the independent variables is $18 \%$. The low value of the coefficient of determination is not an indicator of poor model fit but just shows the predictive power of the independent variables.

Having a high coefficient of determination masks other problems with the data and is not necessarily an indication of good output for analysis. It indicates the strength of association between the independent variables and employee's WPEB. Relying on the coefficient of determination $\left(R^{2}\right)$ can be misleading and thus researchers need to look out for other indicators and analysis (Renaud \& Victoria-Feser, 2010). The adjusted $R^{2}$ values are .155. It takes into account the data sample size and the number of independent variables (9) in each sample to give an unbiased estimate of the fraction of variance explained. The data met the assumption of independent errors and residual auto-correlation (Durbin-Watson value $=1.80$ ) and within the generally accepted benchmark of 0 to 4 (Bernal, Gasparrini, Artundo, \& McKee, 2013; Galindo \& Méndez, 2014).

In Table 4, the descriptive of the predictor variables of employee workplace pro-environmental behaviors (WPEB) is presented. The dependent construct WPEB has a mean score of 3.06 ( $\mathrm{SD}=.495)$. SME employees reported varying levels of PEB. The level of PEB may be due to the concerted efforts and systematic approach in tackling environmental problems and the high level of proximal attendant problems. All the constructs were measured on a Likert scale of 1 to 5 . Employee's social norm was highest among the predictor variables $3.99(\mathrm{SD}=0.875)$ and this is attributable to their collectivist culture. Intention to act reported a high mean score of $3.70(\mathrm{SD}=0.918)$. This is positively related to high scores in social norm and suggests that employees have a strong intent to exhibit PEB in the workplace. Environmental awareness and information need had a mean score of $3.62(\mathrm{SD}=0.718,0.88)$.

Table 4 Mean values, standard deviation for the predictor variables affecting employee workplace pro-environmental behavior

\begin{tabular}{llll}
\hline Item statistics & China (T1) & & Std. \\
\hline Item & Mean & $\begin{array}{l}\text { Stdiation } \\
\text { deviti }\end{array}$ & 296 \\
\hline PEBTOTA & 3.06 & 0.495 & 296 \\
SUSTOAL & 3.39 & 0.561 & 296 \\
ATTTOTAL & 3.21 & 1.02 & 296 \\
INFNTOTAL & 3.62 & 0.888 & 296 \\
INTACTTOTAL & 3.70 & 0.918 & 296 \\
EATOTAL & 3.62 & 0.632 & 296 \\
PBCTOTAL & 3.44 & 0.703 & 296 \\
SITTOTAL & 3.63 & 0.718 & 296 \\
SNTOTAL & 3.99 & 0.875 & 296 \\
HABTOTAL & 3.31 & 0.719 &
\end{tabular}


In the workplace, the employees indicated the desire to have more environmentally friendly facilities and high awareness of environmental problems. Perceived behavior control 3.44 ( $\mathrm{SD}=0.703)$ was much lower than intention to act. However, employees' attitude towards WPEB was low at 3.21 ( $\mathrm{SD}=1.020$ ) when compared to social norms. Sustainable actions mean score 3.39 and habits mean score of 3.31 are low when compared to high mean scores of environmental awareness 3.62 and intention to act. Low habit scores of the employees signify that pro-environmental behaviors have not become a repeated action in their behaviors.

In Table 5, NPAR is the number of parameters estimated in the model. In the saturated model, there are 55 parameters. For our tested (default) model, there are 38 parameters The Chi-square and degree of freedom is 33.092/17 and is non-significant at .011. One rule of thumb suggests that many paths have been dropped if this index exceeds 2 or 3 . The CMIN/DF value is 1.947 and acceptable.

In Table 5, the RMR value is .041 and indicates a good fit. RMR values close to 0 indicate a better model fit. The GFI (goodness of fit index) was devised by Jöreskog and Sörbom (1984). This should exceed .9 for a good model. For the saturated model, it will be a perfect 1. In the model, GFI value is .978 and a good indicator of good fit. GFI is less than or equal to 1 , a value of 1 indicates a perfect fit. The AGFI (adjusted goodness of fit index) takes into account the degrees of freedom available for testing the model. In the model, the AGFI is 0.927 . The AGFI is bounded above by one, which indicates a perfect fit.

The root mean square error of approximation (RMSEA) estimates lack of fit compared to the saturated model (see Table 5). RMSEA of .05 or less indicates good fit, and .08 or less adequate fit. The RMSEA value is .057 . Rule of thumb suggests that RMSEA of about .05 or less would indicate a close fit of the mode and is based on subjective judgment. Based on their experience with RMSEA, Browne, Cudeck, Bollen, and Long (1993) suggest that a RMSEA of .05 or less indicates a "close fit".

\section{Structural equation modeling}

Structural equation modeling (SEM) ranks among the popular methods used in academic research for modeling (Hooper, Coughlan, \& Mullen, 2008; Kline, 2015; Ullman \& Bentler, 2003). It is basically a statistical process that facilitates the estimation

Table 5 Model fit indices

\begin{tabular}{|c|c|c|c|c|c|}
\hline Model (China, T1) & NPAR & CMIN & $\mathrm{DF}$ & $P$ & CMIN/DF \\
\hline Default model & 38 & 33.092 & 17.000 & 0.011 & 1.947 \\
\hline Saturated model & 55 & 0.000 & 0.000 & 0.000 & \\
\hline Independence model & 10 & 215.770 & 45.000 & 0.000 & 4.795 \\
\hline \multirow[t]{2}{*}{ Zero model } & 0 & 1475.000 & 55.000 & 0.000 & 26.818 \\
\hline & $\mathrm{RMR}$ & GFI & AGFI & PGFI & \\
\hline Default model & 0.041 & 0.978 & 0.927 & 0.302 & \\
\hline Saturated model & 0.000 & 1.000 & & & \\
\hline Independence model & 0.214 & 0.854 & 0.821 & 0.698 & \\
\hline \multirow[t]{2}{*}{ Zero model } & 0.324 & 0.000 & 0.000 & 0.000 & \\
\hline & RMSEA & LO 90 & HI 90 & PCLOSE & \\
\hline Default model & 0.057 & 0.027 & 0.085 & 0.320 & \\
\hline Independence model & 0.113 & 0.098 & 0.129 & 0.000 & \\
\hline
\end{tabular}


of causal relations between variables (Byrne, 2013; Pearl, 2012). SEM consists of three basic components, factor analysis, path analysis, and the equation models. The use of SEM in social psychology human behavior-environmental behavior studies enjoys wide usage due to its flexibility and ability to incorporate many variables and test explanatory variables. SEM is robust because it combines multi-regression and factor analysis (Hair, Black, Babin, \& Anderson, 2010).

\section{Critical ratios and regression weights}

The structural equation model and regression weights of the predictor variables in China are represented with their critical ratios and covariance's in Fig. 2 and Table 4. The general rule is if the critical ratio $(\mathrm{CR})$ is $>1.96$ for a regression weight, that path is significant at the .05 levels or better and the estimated path parameter is significant. In the $p$ value column, three asterisks $\left(^{(* *)}\right)$ indicate significance smaller than .001 . The upwards arrow $(\uparrow)$ indicates the critical ratio and the significance of factor covariance of the predictor variables. The significance of estimated covariance's among the latent variables is assessed in the same manner: if $C R>1.96$, the factor covariance is significant. However, an inductive and deductive approach was used to check the direct and indirect effects of the variables.

The regression weights and covariance of the predictor variables are shown in Table 6 . Perceived behavior control (HS1), intention to act (HS2), sustainable actions (HS3), environmental attitude (HS4), and social norms (HS5) significantly influence workplace environmental behavior (PEBTOTA). These variables have a direct and indirect influence on workplace pro-environmental behavior and confirm the need to adopt a holistic perspective in investigating factors that influence WPEB. Both socials norms and

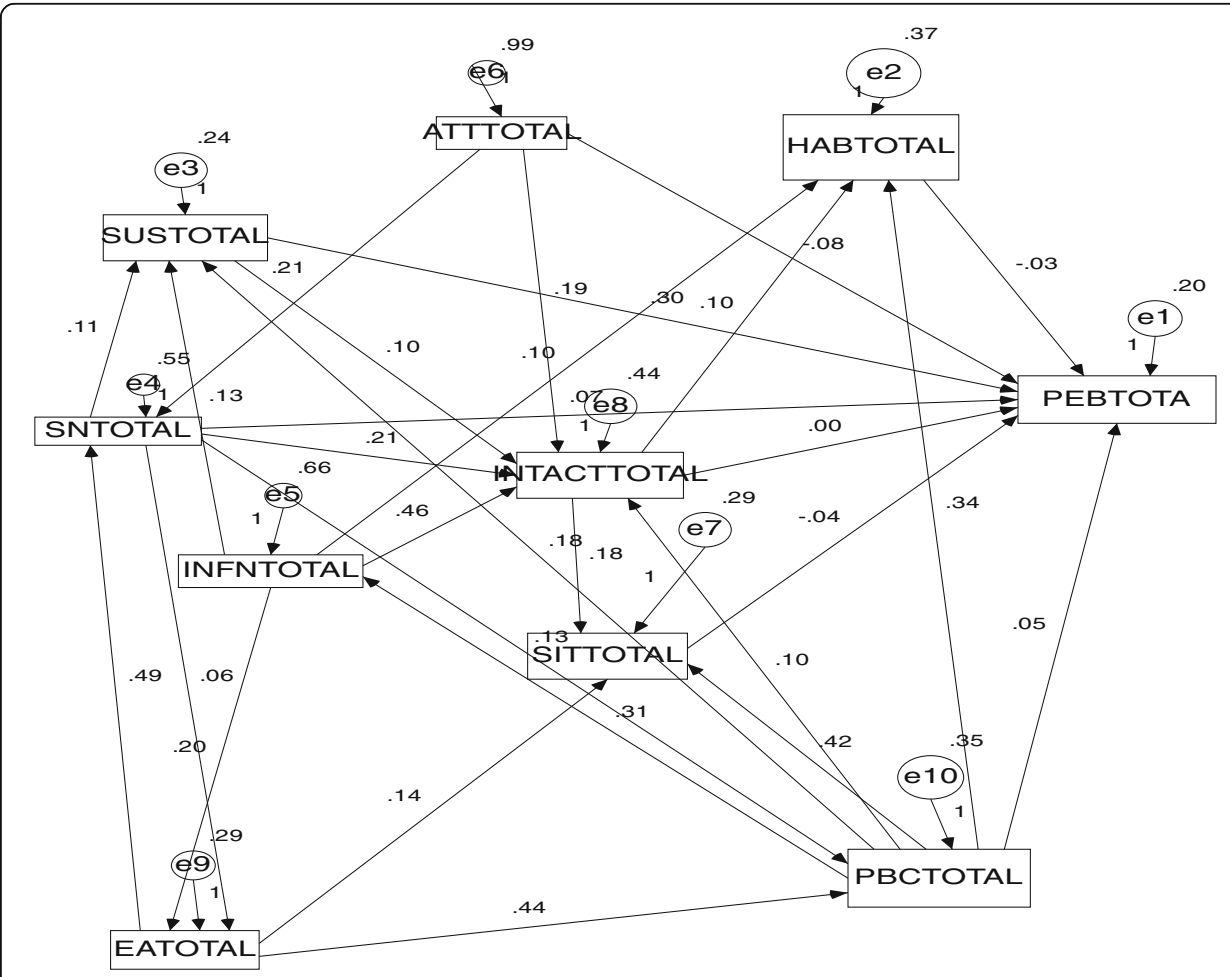

Fig. 2 Structural equation model china (T1) 
Table 6 Regression weights China (T1)

\begin{tabular}{|c|c|c|c|c|c|c|c|}
\hline & & & Estimate & S.E. & C.R. & $P$ & Label \\
\hline SNTOTAL & $\leftarrow$ & ATTTOTAL & 0.212 & 0.045 & 4.764 & **** & $\mathrm{CO}^{1}$ \\
\hline SUSTOTAL & $\leftarrow$ & PBCTOTAL & 0.182 & 0.048 & 3.842 & $* * *$ & $\mathrm{CO}^{2}$ \\
\hline SUSTOTAL & $\leftarrow$ & INFNTOTAL & 0.127 & 0.036 & 3.484 & $* * *$ & $\mathrm{CO}^{3}$ \\
\hline SUSTOTAL & $\leftarrow$ & SNTOTAL & 0.107 & 0.037 & 2.898 & 0.004 & $\mathrm{CO}^{4}$ \\
\hline INTACTTOTAL & $\leftarrow$ & PBCTOTAL & 0.099 & 0.067 & 1.482 & 0.138 & \\
\hline INTACTTOTAL & $\leftarrow$ & SUSTOTAL & 0.102 & 0.08 & 1.279 & 0.201 & \\
\hline INTACTTOTAL & $\leftarrow$ & SNTOTAL & 0.208 & 0.053 & 3.954 & $* * *$ & $\mathrm{CO}^{5}$ \\
\hline INTACTTOTAL & $\leftarrow$ & INFNTOTAL & 0.463 & 0.051 & 9.148 & $* * *$ & $\mathrm{CO}^{6}$ \\
\hline INTACTTOTAL & $\leftarrow$ & ATTTOTAL & 0.188 & 0.041 & 4.577 & $* * *$ & $\mathrm{CO}^{7}$ \\
\hline HABTOTAL & $\leftarrow$ & PBCTOTAL & 0.342 & 0.058 & 5.939 & $* * *$ & $\mathrm{CO}^{8}$ \\
\hline SITTOTAL & $\leftarrow$ & EATOTAL & 0.145 & 0.064 & 2.248 & 0.025 & $\mathrm{CO}^{9}$ \\
\hline SITTOTAL & $\leftarrow$ & PBCTOTAL & 0.42 & 0.056 & 7.442 & $* * *$ & $\mathrm{CO}^{10}$ \\
\hline SITTOTAL & $\leftarrow$ & INTACTTOTAL & 0.178 & 0.041 & 4.384 & $* * *$ & $\mathrm{CO}^{11}$ \\
\hline HABTOTAL & $\leftarrow$ & INTACTTOTAL & 0.097 & 0.051 & 1.886 & 0.059 & \\
\hline HABTOTAL & $\leftarrow$ & INFNTOTAL & 0.097 & 0.051 & 1.887 & 0.059 & \\
\hline PEBTOTA & $\leftarrow$ & HABTOTAL & -0.032 & 0.044 & -0.738 & 0.461 & $\mathrm{HNS}^{1}$ \\
\hline PEBTOTA & $\leftarrow$ & PBCTOTAL & 0.053 & 0.053 & 1 & 0.317 & HS1 \\
\hline PEBTOTA & $\leftarrow$ & INTACTTOTAL & -0.001 & 0.037 & -0.022 & 0.983 & HS2 \\
\hline PEBTOTA & $\leftarrow$ & SITTOTAL & -0.037 & 0.049 & -0.75 & 0.454 & $\mathrm{HNS}^{4}$ \\
\hline PEBTOTA & $\leftarrow$ & SUSTOTAL & 0.3 & 0.053 & 5.66 & $* * *$ & HS3 \\
\hline PEBTOTA & $\leftarrow$ & ATTTOTAL & -0.079 & 0.028 & -2.823 & 0.005 & HS4 \\
\hline PEBTOTA & $\leftarrow$ & SNTOTAL & 0.075 & 0.035 & 2.109 & 0.035 & HS5 \\
\hline EATOTAL & $\leftarrow$ & INFNTOTAL & 0.204 & 0.044 & 4.683 & $* * *$ & $\mathrm{CO}^{12}$ \\
\hline INFNTOTAL & $\leftarrow$ & PBCTOTAL & 0.308 & 0.08 & 3.864 & $* * *$ & $\mathrm{CO}^{13}$ \\
\hline PBCTOTAL & $\leftarrow$ & EATOTAL & 0.441 & 0.07 & 6.301 & $* * *$ & $\mathrm{CO}^{14}$ \\
\hline SNTOTAL & $\leftarrow$ & EATOTAL & 0.49 & 0.196 & 2.503 & 0.012 & $\mathrm{CO}^{15}$ \\
\hline EATOTAL & $\leftarrow$ & SNTOTAL & 0.055 & 0.106 & 0.52 & 0.603 & \\
\hline PBCTOTAL & $\leftarrow$ & SNTOTAL & 0.131 & 0.047 & 2.782 & 0.005 & $\mathrm{CO}^{16}$ \\
\hline
\end{tabular}

CO covariance, HS hypothesis supported, HNS hypothesis not supported

*** indicate significance smaller than .001

sustainable actions were strong indicators of WPEB. Three predictor variables also had strong loadings and covariance with social norms, attitude to social norms loaded strongly $\left(\mathrm{CO}^{1}\right)$, social norms to intention to act loadings and covariance were significant $\left(\mathrm{CO}^{5}\right)$, social norms to perceived behavior control covariance and loading were also strong $\left(\mathrm{CO}^{16}\right)$, environmental awareness also positively influenced social norms $\left(\mathrm{CO}^{15}\right)$. This implies that attitude, intention to act, environmental awareness, and perceived behavior control influenced workplace pro-environmental behavior indirectly through social norms.

Similarly, sustainable actions positively influenced WPEB; however, three other predictor variables also influenced WPEB indirectly through sustainable actions. Both perceived behavior control $\left(\mathrm{CO}^{2}\right)$ and information need $\left(\mathrm{CO}^{3}\right)$ influenced sustainable actions significantly with high loading. Social norms also had lower loading and covariance than the other two variables to sustainable actions. Other covariance's and factor loading are information need to intention to act is significant and has the highest 
critical value and factor loading $\left(\mathrm{CO}^{6}\right)$, the covariance between attitude to intention to act is also significant $\left(\mathrm{CO}^{7}\right)$ and perceived behavior control to habit $\left(\mathrm{CO}^{8}\right)$. Perceived behavior control loaded strongly with Situational factors and significant $\left(\mathrm{CO}^{10}\right)$ with information need $\left(\mathrm{CO}^{13}\right)$. Environmental awareness loaded poorly with situational actors $\left(\mathrm{CO}^{9}\right)$, intention to act to situational factors covariance is significant $\left(\mathrm{CO}^{11}\right)$. Information need to environment awareness covariance and factor loading are significant also; the factor loading of environmental awareness to perceived behavior control is significant and high when compared to the loading of other factors.

\section{Discussion}

The result reveals direct and indirect relationship among the predictor factors that shape SME employees WPEB. Five predictor variables (perceived behavior control, intention to act, sustainable actions, attitude, and social norms directly and indirectly significantly influenced SMEs employee WPEB. This finding is supported by previous research findings on the positive effect of social norms on pro-environmental behavior (Blok et al., 2015). The strength of social norms among the SME employees suggests that where social norms are strong and positive, it should influence positive pro-environmental behavior and if the social norm is weak the positive effect is low. Social norms in China are strong due to the collectivist nature of the society, also the level of awareness of environmental problems also serves as a major influence of social norms. Situational factors and conditions can also hinder WPEB depending on the presence or absence of several other predictor variables (Chou, 2014). In China, the tendency of SME employees to behave positively towards the environment is dependent on the strong effect of social norms, situational conditions, and other intervening factors. Though environmental problems are prevalent in China, the concerted effort of all stakeholders most especially the citizens and local community often serves as a deterrent. This community-based ownership and place attachment behaviors in China facilitate context and localized monitoring by residents without much reliance on government. The main predictors of SME employees WPEB were influenced significantly by some other predictor variables, which had an indirect effect on workplace pro-environmental behavior. The results indicate that sustainable actions are indirectly influenced by perceived behavior control, information need and social norm. Social norms are also indirectly influenced by attitude and environmental awareness.

The effect of these predictor variables on WPEB confirms the complexity in investigating environmental behavior and the fallacy of using single constructs to explain environmental and human behavior. The analysis further suggests that though some variables are not significant and have weak, negative relationships and loading, the realities suggest a complex web of systematic relationships. For instance, though intention to act was low, this is influenced by social norms, information need, and attitude.

Sustainable actions connote repeat positive behaviors or habits that enhance PEB and thus measuring the habit construct and sustainable actions construct are inter-related. It is also evident that perceived behavior control has a strong influence on the nature of habit strength. Employees indicated that the nature of perceived behavior control in their workplace hindered the formation of strong positive habits. Thus, SMEs play a major role in ensuring that they provide working conditions that will favor positive WPEB. Finally, the usage of inductive and deductive reasoning enhanced the 
unbundling of complex inter-relationship among the variables and this is supported by other researchers (Babbie, 2015; Gray, 2013; Ritchie, Lewis, Nicholls, \& Ormston, 2013).

\section{Conclusions}

These outcomes are important to policymakers, health organizations, doctors, researchers, government agencies, and environmental stakeholders. Investigating the predictors of SMEs employee's pro-environmental behavior in China is important for policy formulation, reducing behaviors that result in health hazards and understanding the system dynamics of different factors in shaping and influencing WPEB. The use of a synthesis of theories as shown in the CADM confirms how different variables influence WPEB. The regression and SEM results also show direct and indirect relationships among the predictor variables. However, the models and analysis indicate significance and non-significance of some predictor variables. The domain of human behavior cannot be reduced to merely statistical analysis but should be supported by logical reasoning and discussions based on the context of the study. Suffice to state that the findings would aid policy makers, SMEs stakeholders, and environmental law authorities in drafting and implementing target-based sustainable environmental regulations, behavioral intervention schemes, and incentives to SMEs.

\section{Limitation of the study}

First, the study location is limited to cities in Jiangsu Province (China). Second, data was obtained via the administration of self-report questionnaires via convenience and snowball methods; this has tendencies of self-bias and selection bias to the environmental perception of responses and representativeness. Respondents are usually faced with the dilemma of providing suitable answers or just completing the questionnaires without reading or understanding the questions. This problem led to the rejection of many uncompleted and improperly completed questionnaires (some respondents just ticked the same response in the questionnaires). Based on the aforementioned, scholars doing future studies should expand the sampling design study scope to include more constructs and informal enterprises.

\section{Recommendations for future research}

Features of human behavior, environmental problems, and environmental behavior are dynamic and complex across all contexts. Thus, researchers are faced with several pathways and research areas to investigate. Researchers should also focus on how organizational culture, motivation, and personality factors affect workplace environmental behavior (Norton, Parker, Zacher, \& Ashkanasy, 2015). Second, the level of economic development and nature of the economy is acknowledged to exert different impacts on employee WPEB. Similarly, recent studies confirm casual linkages between these economic indices and PEB (Çarkoğlu \& Kentmen-Çin, 2015). Thus, gaining an industry-based, rural-urban location-based, and socio-demographic-based understanding of how the global economy shapes and influences pro-environmental behaviors at the micro and individual level could enhance the understanding of the diverse antecedents of WPEB. 


\section{Abbreviations}

CADM: Comprehensive action determination model; PEB: Pro-environmental behavior; SEM: Structural equation modeling; SMEs: Small and medium-sized enterprises; WPEB: Workplace pro-environmental behavior

\section{Acknowledgements}

We would like to acknowledge the reviews and inputs of several anonymous researchers and research work of leading scholars on workplace pro-environmental behavior. We are grateful to Prof. Vincent Blok MBA, of Wageningen University for the permission to adapt his questionnaire to this study.

\section{Funding}

The authors received no funding for the design of the study, data collection, analysis, and interpretation of data or the writing of the manuscript.

\section{Availability of data and materials}

The datasets used and/or analyzed during the current study are available from the corresponding author on reasonable request.

\section{Authors' contributions}

The corresponding author AB developed the research idea and worked on the key section of this study. The author JD supervised the data collection and analysis of this study and revision of the final manuscript. Both authors read and approved the final manuscript.

\section{Competing interests}

The authors declare that they have no competing interests.

\section{Publisher's Note}

Springer Nature remains neutral with regard to jurisdictional claims in published maps and institutional affiliations.

Received: 25 October 2018 Accepted: 20 March 2019

Published online: 18 April 2019

\section{References}

Ajzen, I. (1991). The theory of planned behavior. Organizational Behavior and Human Decision Processes, 50(2), 179-211.

Ajzen, l., \& Madden, T. J. (1986). Prediction of goal-directed behavior: Attitudes, intentions, and perceived behavioral control. Journal of Experimental Social Psychology, 22(5), 453-474.

Alam, S. (2013). Routledge handbook of international environmental law. Routledge.

Atkinson, R., \& Flint, J. (2001). Accessing hidden and hard-to-reach populations: Snowball research strategies. Social Research Update, $33(1), 1-4$

Ayyagari, M., Beck, T., \& Demirguc-Kunt, A. (2007). Small and medium enterprises across the globe. Small Business Economics, 29(4), 415-434.

Ayyagari, M., Demirgüç-Kunt, A., \& Maksimovic, V. (2011). Small vs. young firms across the world: contribution to employment, job creation, and growth. In World Bank Policy Research Working Paper (5631).

Ayyagari, M., Demirguc-Kunt, A., \& Maksimovic, V. (2014). Who creates jobs in developing countries? Small Business Economics, $43(1), 75-99$.

Babbie, E. R. (2015). The practice of social research. Nelson Education.

Bamberg, S., \& Möser, G. (2007). Twenty years after Hines, Hungerford, and Tomera: A new meta-analysis of psycho-social determinants of pro-environmental behaviour. Journal of Environmental Psychology, 27(1), 14-25.

Bauchet, J., \& Morduch, J. (2013). Is micro too small? Microcredit vs. SME finance. World Development, 43, 288-297.

Beaton, D. E., Bombardier, C., Guillemin, F., \& Ferraz, M. B. (2000). Guidelines for the process of cross-cultural adaptation of self-report measures. Spine, 25(24), 3186-3191.

Blok, V., Wesselink, R., Studynka, O., \& Kemp, R. (2015). Encouraging sustainability in the workplace: a survey on the proenvironmental behaviour of university employees. Journal of Cleaner Production, 106, 55-67.

Boiral, O., Paillé, P., \& Raineri, N. (2015). The Nature of Employees' Pro-environmental Behaviors.

Brislin, R. W. (1970). Back-translation for cross-cultural research. Journal of Cross-Cultural Psychology, 1(3), 185-216.

Browne, M. W., Cudeck, R., Bollen, K. A., \& Long, J. S. (1993). Alternative ways of assessing model fit. Sage Focus Editions, 154, 136-136.

Byrne, B. M. (2013). Structural equation modeling with AMOS: basic concepts, applications, and programming. Routledge.

Canfa, W. (2006). Chinese environmental law enforcement: current deficiencies and suggested reforms. Vermont Journal Environmental Law, 8, 159.

Cantor, D. E., Morrow, P. C., \& Montabon, F. (2012). Engagement in environmental behaviors among supply chain management employees: An organizational support theoretical perspective. Journal of Supply Chain Management, 48(3), 33-51.

Çarkoğlu, A., \& Kentmen-Çin, Ç. (2015). Economic development, environmental justice, and pro-environmental behavior. Environmental Politics, 24(4), 575-597.

Chen, X., Peterson, M. N., Hull, V., Lu, C., Hong, D., \& Liu, J. (2013). How perceived exposure to environmental harm influences environmental behavior in urban China. Ambio, 42(1), 52-60.

Chou, C.-J. (2014). Hotels' environmental policies and employee personal environmental beliefs: Interactions and outcomes. Tourism Management, 40, 436-446.

Cliff, N. (1988). The eigenvalues-greater-than-one rule and the reliability of components. Psychological Bulletin, 103(2), 276.

Dahm, M. J., Samonte, A. V., \& Shows, A. R. (2009). Organic foods: Do eco-friendly attitudes predict eco-friendly behaviors? Journal of American College Health, 58(3), 195-202. 
De Young, R. (2000). New ways to promote proenvironmental behavior: Expanding and evaluating motives for environmentally responsible behavior. Journal of Social Issues, 56(3), 509-526.

Dixon, J., Scura, L., Carpenter, R., \& Sherman, P. (2013). Economic analysis of environmental impacts. Routledge.

Eaton, S., \& Kostka, G. (2014). Authoritarian environmentalism undermined? Local leaders' time horizons and environmental policy implementation in China. The China Quarterly, 218, 359-380.

Economy, E. C. (2011). The river runs black: The environmental challenge to China's future. Cornell University Press.

Eisenberg, N., Lennon, R., \& Roth, K. (1983). Prosocial development: a longitudinal study. Developmental Psychology, $19(6), 846$.

Etzion, D. (2007). Research on organizations and the natural environment, 1992-present: a review. Journal of Management, 33(4), 637-664.

Fakieh, Bahjat, Blount, Yvette, \& Busch, Peter. (2016). SMEs and cloud computing: the benefits to the national economy and global competitiveness. Paper presented at the Conference: The 13 th European Mediterranean \& Middle Eastern Conference on Information Systems, EMCIS.

Fishbein, M. (1979). A theory of reasoned action: some applications and implications.

Galindo, M.-Á., \& Méndez, M. T. (2014). Entrepreneurship, economic growth, and innovation: Are feedback effects at work? Journal of Business Research, 67(5), 825-829.

Gatersleben, B., Steg, L., \& Vlek, C. (2002). Measurement and determinants of environmentally significant consumer behavior. Environment and Behavior, 34(3), 335-362.

Gifford, R., \& Nilsson, A. (2014). Personal and social factors that influence pro-environmental concern and behaviour: A review. International Journal of Psychology, 49(3), 141-157.

Gray, D. E. (2013). Doing research in the real world. Sage.

Hair, J. F., Black, W. C., Babin, B. J., \& Anderson, R. E. (2010). SEM basics: A supplement to multivariate data analysis. Multivariate data analysis.

Hannigan, J. (2014). Environmental sociology. Routledge.

Harris, P. G. (2006). Environmental perspectives and behavior in China synopsis and bibliography. Environment and Behavior, 38(1), 5-21.

He, G., Lu, Y., Mol, A. P. J., \& Beckers, T. (2012). Changes and challenges: China's environmental management in transition. Environmental Development, 3, 25-38.

He, G., Zhang, L., Mol, A. P. J., Wang, T., \& Lu, Y. (2014). Why small and medium chemical companies continue to pose severe environmental risks in rural China. Environmental Pollution, 185, 158-167.

Hendrickson, A. E., \& White, P. O. (1964). Promax: A quick method for rotation to oblique simple structure. British Journal of Statistical Psychology, 17(1), 65-70.

Hines, J. M., Hungerford, H. R., \& Tomera, A. N. (1987). Analysis and synthesis of research on responsible environmental behavior: A meta-analysis. The Journal of Environmental Education, 18(2), 1-8.

Hooper, D., Coughlan, J., \& Mullen, M. (2008). Structural equation modelling: Guidelines for determining model fit. Articles, 2.

Huang, C., Zhang, M., Zou, J., Zhu, A.-X., Chen, X., Mi, Y., et al. (2015). Changes in land use, climate and the environment during a period of rapid economic development in Jiangsu Province, China. Science of the Total Environment, 536, 173-181.

Jamali, D., Lund-Thomsen, P., \& Jeppesen, S. (2015). SMEs and CSR in developing countries. Business \& Society, 56(1), 11-22. https://doi.org/10.1177/0007650315571258.

Jensen, B. B. (2002). Knowledge, action and pro-environmental behaviour. Environmental Education Research, 8(3), 325-334

Jöreskog, K. G., \& Sörbom, D. (1984). LISREL-VI user's guide.

Kline, R. B. (2015). Principles and practice of structural equation modeling. Guilford publications.

Klöckner, C. A. (2013). A comprehensive model of the psychology of environmental behaviour-a meta-analysis. Global Environmental Change, 23(5), 1028-1038.

Klöckner, C. A., \& Blöbaum, A. (2010). A comprehensive action determination model: Toward a broader understanding of ecological behaviour using the example of travel mode choice. Journal of Environmental Psychology, 30(4), 574-586.

Klöckner, C. A., \& Matthies, E. (2012). Two pieces of the same puzzle? Script-based car choice habits between the influence of socialization and past behavior. Journal of Applied Social Psychology, 42(4), 793-821.

Kollmuss, A., \& Agyeman, J. (2002). Mind the gap: why do people act environmentally and what are the barriers to proenvironmental behavior? Environmental Education Research, 8(3), 239-260

Kostka, G. (2014). Barriers to the implementation of environmental policies at the local level in China. In World Bank Policy Research Working Paper (7016).

Larson, L. R., Stedman, R. C., Cooper, C. B., \& Decker, D. J. (2015). Understanding the multi-dimensional structure of proenvironmental behavior. Journal of Environmental Psychology, 43, 112-124

Li, W., Liu, J., \& Li, D. (2012). Getting their voices heard: Three cases of public participation in environmental protection in China. Journal of Environmental Management, 98, 65-72.

Lindenberg, S., \& Steg, L. (2007). Normative, gain and hedonic goal frames guiding environmental behavior. Journal of Social Issues, 63(1), 117-137.

Liu, X., Liu, B., Shishime, T., Yu, Q., Bi, J., \& Fujitsuka, T. (2010). An empirical study on the driving mechanism of proactive corporate environmental management in China. Journal of Environmental Management, 91 (8), 1707-1717.

Liu, Y., \& Bai, Y. (2014). An exploration of firms' awareness and behavior of developing circular economy: an empirical research in China. Resources, Conservation and Recycling, 87, 145-152.

Lülfs, R., \& Hahn, R. (2014). Sustainable behavior in the business sphere: A comprehensive overview of the explanatory power of psychological models. Organization \& Environment, 27, 43-64. https://doi.org/10.1177/1086026614522631.

McDonald, F. V. (2014). Developing an integrated conceptual framework of pro-environmental behavior in the workplace through synthesis of the current literature. Administrative Sciences, 4(3), 276-303.

McLeod, S. (2009). Jean Piaget. In Simply psychology.

Norton, T. A., Parker, S. L., Zacher, H., \& Ashkanasy, N. M. (2015). Employee green behavior a theoretical framework, multilevel review, and future research agenda. Organization \& Environment, 28(1), 103-125.

Nunnally, J. C., \& Bernstein, I. H. (1994). The assessment of reliability. Psychometric Theory, 3(1), 248-292.

Ones, D. S., \& Dilchert, S. (2013). Measuring, understanding, and influencing employee green behaviors. In Green organizations: Driving change with 10 psychology (pp. 115-148). 
Osbaldiston, R., \& Schott, J. P. (2011). Environmental sustainability and behavioral science: Meta-analysis of proenvironmental behavior experiments. Environment and Behavior. https://doi.org/10.1177/0013916511402673.

Osborne, J. W., \& Costello, A. B. (2009). Best practices in exploratory factor analysis: Four recommendations for getting the most from your analysis. Pan-Pacific Management Review, 12(2), 131-146.

Ouellette, J. A., \& Wood, W. (1998). Habit and intention in everyday life: the multiple processes by which past behavior predicts future behavior. Psychological Bulletin, 124(1), 54.

Paillé, P., \& Mejía-Morelos, J. H. (2014). Antecedents of pro-environmental behaviours at work: The moderating influence of psychological contract breach. Journal of Environmental Psychology, 38, 124-131.

Parker, C. M., Redmond, J., \& Simpson, M. (2009). A review of interventions to encourage SMEs to make environmental improvements. Environment and Planning C: Government and Policy, 27(2), 279-301.

Pearl, J. (2012). The causal foundations of structural equation modeling. DTIC Document.

Renaud, O., \& Victoria-Feser, M.-P. (2010). A robust coefficient of determination for regression. Journal of Statistical Planning and Inference, 140(7), 1852-1862.

Ritchie, J., Lewis, J., Nicholls, C. M. N., \& Ormston, R. (2013). Qualitative research practice: a guide for social science students and researchers. Sage.

Robertson, J. L., \& Barling, J. (2013). Greening organizations through leaders' influence on employees' pro-environmental behaviors. Journal of Organizational Behavior, 34(2), 176-194.

Ruepert, A., Keizer, K., Steg, L., Maricchiolo, F., Carrus, G., Dumitru, A., et al. (2016). Environmental considerations in the organizational context: A pathway to pro-environmental behaviour at work. Energy Research \& Social Science, 17, 59-70.

Schwartz, S. H., \& Howard, J. A. (1981). A normative decision-making model of altruism. Altruism and Helping Behaviour: Personality and Developmental Perspectives. JP Rushton and R. M. Sorrentino. Hillsdale et al, (pp. 189-211).

Steg, L., Bolderdijk, J. W., Keizer, K., \& Perlaviciute, G. (2014). An integrated framework for encouraging pro-environmental behaviour: The role of values, situational factors and goals. Journal of Environmental Psychology, 38, 104-115.

Steg, L., \& Vlek, C. (2009). Encouraging pro-environmental behaviour: An integrative review and research agenda. Journal of Environmental Psychology, 29(3), 309-317.

Su, B., Heshmati, A., Geng, Y., \& Yu, X. (2013). A review of the circular economy in China: Moving from rhetoric to implementation. Journal of Cleaner Production, 42, 215-227.

Sudbury Riley, L., Kohlbacher, F., \& Hofmeister, A. (2012). A cross-cultural analysis of pro-environmental consumer behaviour among seniors. Journal of Marketing Management, 28(3-4), 290-312.

Tavakol, M., \& Dennick, R. (2011). Making sense of Cronbach's alpha. International Journal of Medical Education, 2, 53.

Triandis, Harry C. (1979). Values, attitudes, and interpersonal behavior. Paper presented at the Nebraska symposium on motivation.

Troschinetz, A. M., \& Mihelcic, J. R. (2009). Sustainable recycling of municipal solid waste in developing countries. Waste Management, 29(2), 915-923.

Turaga, R. M. R., Howarth, R. B., \& Borsuk, M. E. (2010). Pro-environmental behavior. Annals of the New York Academy of Sciences, 1185(1), 211-224

Ullman, J. B., \& Bentler, P. M. (2003). Structural equation modeling. Wiley.

Unsworth, K. L., Dmitrieva, A., \& Adriasola, E. (2013). Changing behaviour: Increasing the effectiveness of workplace interventions in creating pro-environmental behaviour change. Journal of Organizational Behavior, 34(2), 211-229.

Vaske, J. J., Beaman, J., \& Sponarski, C. C. (2016). Rethinking internal consistency in Cronbach's alpha. Leisure Sciences, 39(2), 163-173.

Verplanken, B., \& Aarts, H. (1999). Habit, attitude, and planned behaviour: is habit an empty construct or an interesting case of goal-directed automaticity? European Review of Social Psychology, 10(1), 101-134.

Verplanken, B., \& Orbell, S. (2003). Reflections on past behavior: A self-report index of habit strength 1. Journal of Applied Social Psychology, 33(6), 1313-1330

Wagner, A. K., Gandek, B., Aaronson, N. K, Acquadro, C., Alonso, J., Apolone, G., et al. (1998). Cross-cultural comparisons of the content of SF-36 translations across 10 countries: results from the IQOLA project. Journal of Clinical Epidemiology, 51(11), 925-932.

Wang, A. (2013). The search for sustainable legitimacy: environmental law and bureaucracy in China.

Xi, B., Li, X., Gao, J., Zhao, Y., Liu, H., Xia, X., et al. (2015). Review of challenges and strategies for balanced urban-rural environmental protection in China. Frontiers of Environmental Science \& Engineering, 9(3), 371-384.

Xiao, C., \& Hong, D. (2010). Gender differences in environmental behaviors in China. Population and Environment, 32(1), 88-104.

Xu, L., Mathiyazhagan, K., Govindan, K., Haq, A. N., Ramachandran, N. V., \& Ashokkumar, A. (2013). Multiple comparative studies of green supply chain management: Pressures analysis. Resources, Conservation and Recycling, 78, 26-35.

Yeomans, K. A., \& Golder, P. A. (1982). The Guttman-Kaiser criterion as a predictor of the number of common factors. The Statistician, 221-229

Yu, X. (2014). Is environment 'a city thing' in China? Rural-urban differences in environmental attitudes. Journal of Environmental Psychology, 38, 39-48.

Zhang, B., Bi, J., Yuan, Z., Ge, J., Liu, B., \& Bu, M. (2008). Why do firms engage in environmental management? An empirical study in China. Journal of Cleaner Production, 16(10), 1036-1045.

Zhang, K.-m., \& Wen, Z.-g. (2008). Review and challenges of policies of environmental protection and sustainable development in China. Journal of Environmental Management, 88(4), 1249-1261. 